\title{
Statistical Downscaling and Projection of Future Air Temperature Changes in Yunnan Province, China
}

\author{
Jiaxu Liu, ${ }^{1,2}$ Sujing Chen, ${ }^{1,2}$ Lijuan Li, ${ }^{1}$ and Jiuyi $\mathrm{Li}^{1}$ \\ ${ }^{1}$ Key Laboratory of Water Cycle and Related Land Surface Processes, Institute of Geographic Sciences and Natural Resources Research, \\ Chinese Academy of Sciences (CAS), Beijing 100101, China \\ ${ }^{2}$ University of CAS, Beijing 100049, China
}

Correspondence should be addressed to Lijuan Li; lilj@igsnrr.ac.cn

Received 1 September 2016; Revised 16 November 2016; Accepted 13 December 2016; Published 17 January 2017

Academic Editor: Roberto Fraile

Copyright (c) 2017 Jiaxu Liu et al. This is an open access article distributed under the Creative Commons Attribution License, which permits unrestricted use, distribution, and reproduction in any medium, provided the original work is properly cited.

\begin{abstract}
The SDSM was employed for downscaling of daily mean temperature of 32 meteorological stations (1954-2014) and future scenarios were generated up to 2100 . The data were daily NCEP/NCAR reanalysis data and the daily mean climate model outputs for the RCP2.6, RCP4.5, and RCP8.5 scenarios from the MRI of Japan. Periodic features were obtained by wavelet analysis. The results showed the following. (1) The pattern of change and the numerical values of the air temperature could be reasonably simulated, with the average $R^{2}$ between observed and generated data being 0.963 for calibration and 0.964 for validation. (2) All scenarios projected increases of different degrees of temperature in all seasons, except for spring in the 2020s. Annually, the most remarkable changes in the 2020s, 2050s, and 2080s were $0.27,1.00$, and $1.84^{\circ} \mathrm{C}$, respectively. Seven dominant periods appeared under RCP4.5 and RCP8.5 from 1954 to 2100; however, an additional period appeared under RCP2.6. (3) In future periods, especially the 2020s, decreases in temperature were significantly located in the center of Yunnan under all three scenarios, whereas there were distinct increases in northwest and southeast Yunnan in most future periods. Besides, the RCP8.5 scenario showed the greatest increase in the 2080s.
\end{abstract}

\section{Introduction}

The Earth's temperature increased by $0.85[0.65-1.06]^{\circ} \mathrm{C}$ from 1880 to 2012 owing to increases in the concentrations of $\mathrm{CO}_{2}$ and other greenhouse gases [1], according to the Fifth Assessment Report (AR5) of the Intergovernmental Panel on Climate Change [2], and the average global temperature has climbed sharply in the past 30 years [3]. Global warming, as characterized by increasing air temperature, has the potential to cause higher evaporation rates and probably accelerates the global hydrological cycle, so its impact on the latter has become the focus of large-scale investigations. In addition, the frequency of occurrence of extreme weather events such as heatwaves and intense and persistent precipitation is likely to increase [4]. There has therefore been a more intense focus and an increase in the number of studies on future changes in the magnitude and intensity of temperature and precipitation. Clearly, general circulation models (GCMs), also referred to as global climate models [5], are the most important and effective techniques for climate impact studies [6].
In order to assess the potential future impact of climate, research has been directed toward the development of GCMs with spatial resolutions of hundreds of kilometers, and important global or continental-scale atmospheric processes, as well as future climate prediction, under different emission scenarios can be reproduced by state-of-the-art GCMs. However, hydrologists are interested in scales of a few kilometers, and, furthermore, hydroclimatic information at finer scales is essential for climate impact studies [7]. Therefore, a technique known as "downscaling" has been developed to bridge the gap between the coarse resolution of GCMs and the need for surface weather variables at regional or local spatial resolutions.

Based on the way of using large-scale GCM information on local scale, downscaling methods can be broadly grouped into two categories: dynamical downscaling (DD) and statistical (or empirical) downscaling (SD) [8]. In DD, the raw GCM outputs are used as boundary conditions to drive a regional climate model (RCM) and produce important information at fine spatial scales $(<50 \mathrm{~km})$. The DD method 
responds in physically consistent ways to different external forcings. However, the major drawbacks of DD are its high computational cost and its complex design [9]. In contrast, SD produces local or station-scale meteorological time series (predictands) by establishing appropriate statistical or empirical relationships between GCMs that are simulated large-scale atmospheric variables (predictors) and surface or troposphere atmospheric features. Generally, compared with $\mathrm{DD}$, the SD method is cheap, computationally undemanding, and readily transferable, so it has been widely used in uncertainty and risk analyses of climate change [10].

According to the techniques involved in its application, the SD approach can be divided into three categories, namely, weather generator, weather typing, and regression/transform function [11], the respective strengths and weaknesses of which have been reviewed by, for example, Fowler et al. (2007) [8], Hewitson and Crane (1996) [12], and Wilby et al. (2002) [13]. The Statistical DownScaling Model (SDSM) is a hybrid of multiple linear regression (MLR) and the stochastic weather generator (SWG) based on downscaling methods [13] and is a promising and performing SD model. A couple of comparative studies [14-16] have shown that the SDSM is relatively simple to handle and operate, and it has been widely applied throughout the world, for example, in America [17], India [6], and Canada [18], owing to its superior capability.

Simultaneously, Chinese researchers have focused increased attention on the SDSM. Most previous work was concentrated on maximum and minimum air temperatures [19] or precipitation [20, 21] for different scales of drainage basin in China. The hot areas in this context are the Yangtze River basin [22] and the Yellow River basin [23]. However, the SDSM has hardly ever been applied to administrative regions in China, such as Yunnan province. Yunnan, with the most concentrated folk communities in China, is a mountainous plateau area with diverse climate and ecology. Hence, it plays a vital role in social-economic development and the protection of biodiversity in China.

Good knowledge of future scenarios of daily mean temperature in Yunnan is critical for grain yield, for planning and management of water resources, and for design of systems for monitoring climate change and will provide valuable information in policy making for local government. Therefore, this study aims to offer a detailed projection of daily mean temperature for Yunnan in the twenty-first century using the SDSM. It strives to (1) examine the potential applicability of SDSM for modeling daily mean temperature in a province-level administration, such as Yunnan, and (2) provide future scenarios for temperature at a local scale from downscaled projections (2011-2100). The results are expected to contribute to the development of current downscaling knowledge for similar subtropical regions of China.

\section{Study Area}

Yunnan province is located in southwestern China and covers a total area of about $39.4 \times 10^{4} \mathrm{~km}^{2}$ between $21.9-29.25^{\circ} \mathrm{N}$ and $97.32-106.12^{\circ} \mathrm{E}$ [24]. It is a plateau at low latitude with a complex landscape. Yunnan is the most southwestern province in China (Figure 1), with the Tropic of Cancer running

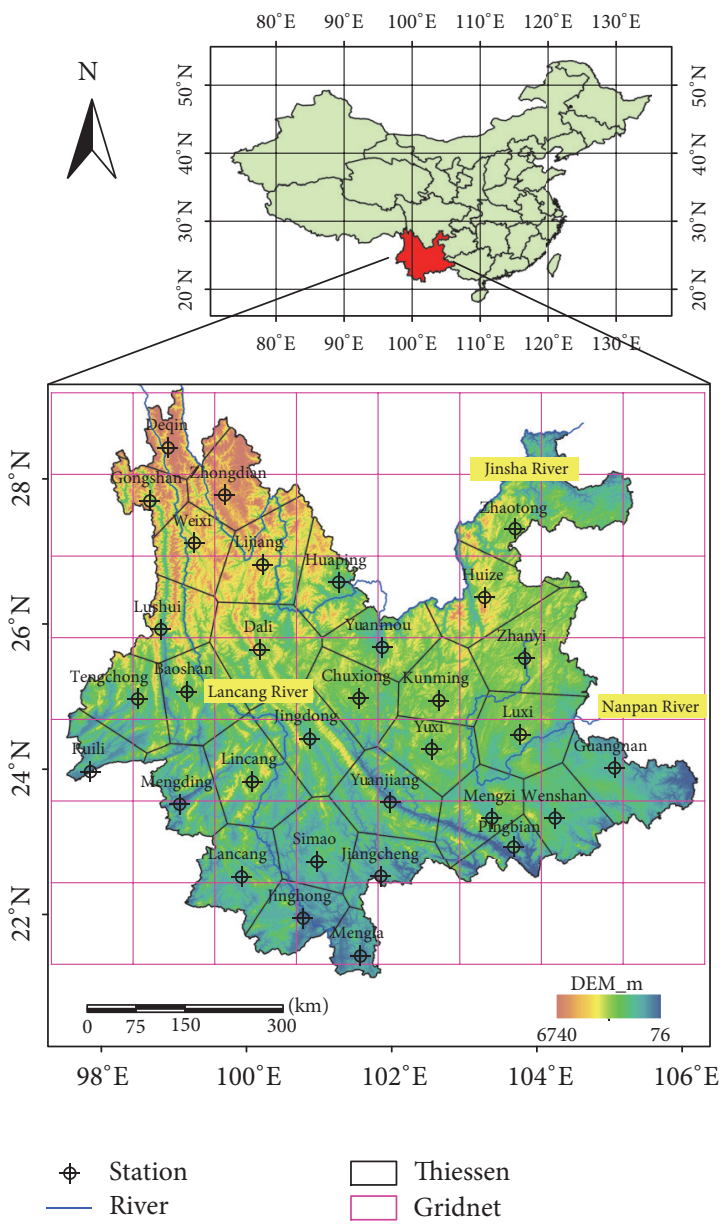

FIGURE 1: Basin profile and distribution of meteorological stations in Yunnan province.

through its southern part. It is a mountainous area with an average elevation of $2000 \mathrm{~m}$ and with high elevations in the northwest and low elevations in the southeast. The climate is typically controlled by the dry continental monsoon in winter and the moist ocean winds in summer. According to its various climates, Yunnan can be divided into seven zones: the plateau climate zone, the southern temperate climate zone, the southern subtropical climate zone, the middle temperate climate zone, the middle subtropical climate zone, the northern subtropical climate zone, and the northern tropical climate zone [25]. There are three main rivers flowing through Yunnan province (Figure 1): the Lancang River (western Yunnan), the Jinsha River (northern Yunnan), and the Nanpan River (eastern Yunnan).

\section{Materials and Methods}

3.1. Data. Three kinds of data were used in this study: observed daily mean air temperature, NCEP reanalysis data, and GCM output data. Observed daily mean air temperatures from 32 meteorological stations (Figure 1) from 1954 to 2014 were collected from the National Climate Center of the China Meteorological Administration (CMA), and all observed 
data series had passed CMA data quality control. Moreover, missing data for one or two days were filled with the average of the neighboring two days' values using SPSS software. The National Centers for Environmental Prediction/National Center for Atmospheric Research (NCEP/NCAR) reanalysis datasets [26-28] for the period 1948-2014 provided the suite of daily atmospheric variables selected as observed large-scale predictors. Outputs of scenarios (Representative Concentration Pathways) RCP2.6, RCP4.5, and RCP8.5 of the third-generation Coupled Global Climate Model (CGCM3) from the Meteorological Research Institute of Japan (MRI) were from 2006 to 2100 [29, 30]. The selected GCM grid boxes are shown in Figure 1. Three scenarios were characterized by a continuously increasing global population with a consequent increase in the emission of greenhouse gas and with a high rate in RCP8.5, a moderate rate in RCP4.5, and a low rate in RCP2.6.

The terrestrial carbon cycle process is an essential component for the accurate estimation of climate change. In CGCM3, the terrestrial biosphere absorbs $\mathrm{CO}_{2}$ from the atmosphere by producing vegetation and releases $\mathrm{CO}_{2}$ into the atmosphere by decomposition of soil organic carbon. The terrestrial carbon cycle model is based on models of the biochemical processes of photosynthesis on the organism leaf level and on a dynamic global vegetation model on the ecosystem-biogeochemical level. What is more, the model contains the interaction mechanism of C3 and C4 photosynthesis plants. The leaf-level photosynthesis model is calculated with a time interval of 30 minutes to 1 hour. On the ecosystem level, the exchange of $\mathrm{CO}_{2}$ between the atmosphere and the ecosystem is evaluated by the difference between net primary production and soil respiration with a time interval of 1 day to 1 month (see [29] for more details).

3.2. Statistical DownScaling Model (SDSM). The SDSM, developed by Wilby et al. (2002) [13], is a decision support tool for assessing the impact of local climate change. It can capture interannual variability better than other statistical downscaling approaches [31]. Multilinear regression is used to derive a statistical relationship between predictors and predictand [32]. Three implicit assumptions are made when using the SDSM to assess regional climate change: (1) the predictors are variables of relevance and are realistically simulated by the GCM; (2) the predictors selected can fully represent the climate change signal; and (3) under altered climate conditions, the relationship is still valid.

In general, five steps are involved when using the SDSM $[10,33]$ : (1) selection of predictors, (2) calibration of model parameters, (3) simulation, (4) validation, and (5) generation of future series based on GCM predictors. With the aim of evaluating model in terms of temperature in Yunnan province, model calibration involved optimizing multiple linear regression equations for daily mean temperature as a function of the selected large-scale atmospheric variable NCEP reanalysis predictors. Then, daily air temperature was simulated by the weather generator of the SDSM, driven by NCEP reanalysis predictors. Evaluation of the model was based on comparison between the simulated and observed daily air temperature series. The downscaled process was unconditional for air temperature, and there was a direct linear relationship between air temperature and the selected predictors.

The SDSM has been applied to produce high-resolution climate change scenarios in a range of geographical contexts $[9,19,34]$. It was used in this study for each station to establish statistical relationships of multiple linear regression between GCM predictors and local climate variables. Daily mean temperature was simulated during the following periods: the 2020s (2011-2040), the 2050s (2041-2070), and the 2080s (2071-2100).

3.3. Wavelet Analysis. Wavelet analysis has many advantages over the fast Fourier transform (FFT) [35] for the analysis of nonstationary data series in which the amplitudes and phases of the harmonic constituents may be changing rapidly in time or space. Whereas an FFT of a nonstationary time series would smear out any detailed information on the changing processes, wavelet analysis attempts to track the evolution of the signal characteristics through the dataset.

The most commonly used wavelet functions are the Morlet wavelet [36], the Haar wavelet [37], and the Mexican hat [38]. The Morlet wavelet has already been validated in geophysical applications among several "mother" wavelets $[39,40]$, and it was therefore adopted in this study. Assuming a wavelet function that satisfies a certain condition, the wavelet transform of the time series can be defined as

$$
W_{f}(a, b)=|a|^{-1 / 2} \Delta t \sum_{i=1}^{n} f(i \Delta t) \Phi\left(\frac{i \Delta t-b}{a}\right),
$$

where $W_{f}(a, b)$ is the wavelet coefficient and $a$ is a frequency parameter that reflects the length of the wavelet period, while $b$ is a time parameter that reflects the wave's translation over time. $\Delta t$ is the sample interval $[41,42]$.

The wavelet coefficient $W_{f}(a, b)$ at different timescales (periods, with a unit of a year, the same as below) can reflect the system's variational characteristics on different timescales. A turning point between positive and negative wave coefficients corresponds to a point of sudden change. The greater the wavelet coefficient, the more significant the variations on this timescale $[43,44]$.

The variance of the wavelet coefficient, the wavelet variance $\operatorname{var}(a)$, can be calculated by computing the sum of the squares of $W_{f}$ and can be described as

$$
\operatorname{var}(a)=\sum_{i=1}^{n}\left[W_{f}(a, b)\right]^{2} .
$$

On a given timescale, the wavelet variance reflects the periodic fluctuation intensity of the time series on this scale. The scale corresponding to the peak value can thus be regarded as the main timescale of this series, that is, the main period [45].

\section{Results and Discussion}

4.1. Calibration and Validation. The study carried out the downscaling process for each station, which produced 20 ensembles (default), and the study then took the mean of 
these ensembles. The model was calibrated and validated using observations of 40 years of data (1954-1993, termed the base period) and the remaining 21 years of data (19942014, termed the late period), respectively. During the calibration process, a monthly submodel was developed and the downscaling process was selected as an unconditional process for daily mean temperature. The predictand was daily mean temperature from the observed surface variables, and the predictor variables were from the NCEP reanalysis data, including near surface specific humidity, mean sea level pressure, near surface relative humidity, geostrophic airflow velocity, mean temperature, zonal velocity component, and meridional velocity component.

The mean air temperature (T_mean) and median air temperature ( $T$ _median) for each month, season, and year were chosen as criteria for evaluating the performance of the SDSM. The T_mean and the T_median of Yunnan province were calculated based on the area weight of a Thiessen polygon (Figure 1) and the same data processing for observations.

Figure 2 shows the modeled and observed air temperatures at monthly and seasonal scales during the calibration and validation periods. $T$ _mean and $T$ _median are well simulated during the calibration period (Figure 3(a)). The error value (EV, equal to simulation minus observation) of $T$ _mean is between -0.04 and $0.06^{\circ} \mathrm{C}$ for 12 months and between -0.02 and $0.03^{\circ} \mathrm{C}$ for four seasons, while the EV of the annual $T$ _mean is only $0.01^{\circ} \mathrm{C}$. The EV of $T$ median is between -0.15 and $0.07^{\circ} \mathrm{C}$ for 12 months and between -0.07 and $0.06^{\circ} \mathrm{C}$ for four seasons, while the $\mathrm{EV}$ of the annual $T$ _median is only $0.04^{\circ} \mathrm{C}$.

On the whole, $T$ _mean and $T$ median are slightly underestimated during the validation period (Figure 3(b)). T_mean values of all months and seasons are underestimated by 0.31 to $0.92^{\circ} \mathrm{C}$ and 0.44 to $0.70^{\circ} \mathrm{C}$, respectively, while the annual $T$ _mean is underestimated by $0.59^{\circ} \mathrm{C}$. $T$ _median values of all months and seasons are underestimated by 0.35 to $1.07^{\circ} \mathrm{C}$ and 0.49 to $0.78^{\circ} \mathrm{C}$, respectively, while the annual $T$ median is underestimated by $0.64^{\circ} \mathrm{C}$.

Simulated versus observed daily mean temperatures in both calibration and validation periods are shown in Figure 3. Overall, it is evident that air temperature is well modeled, because both the slope and $R^{2}$ are near 1 for the calibration (Figure 3(a)) and validation (Figure 3(b)) periods; what is more, the two slopes $(0.9559,0.9668)$ are also close to 1.0.

\subsection{Projected Changes for Future Climate Scenarios}

\subsubsection{Variation of Weighted Average Air Temperature for Yunnan Province}

(1) Variation of Monthly and Seasonal Air Temperatures. Mean monthly scenarios in Yunnan province (Figure 4) show warmer conditions in the periods of the 2020s, 2050s, and 2080s compared with the base period (1954-1993). There is much difference among RCP2.6, RCP4.5, and RCP8.5 scenarios with regard to air temperature changes. A wide range of air temperature changes in different months and under different scenarios is anticipated. A significant increase in mean monthly temperature is predicted from May to August and from October to January under all three scenarios. The increases are in the ranges $0.14-0.56^{\circ} \mathrm{C}, 0.00-1.18^{\circ} \mathrm{C}$, and $0.04-1.15^{\circ} \mathrm{C}$ under the RCP2.6 scenario (Figure $4(\mathrm{a})$ ), $0.12-0.88^{\circ} \mathrm{C}, 0.11-1.35^{\circ} \mathrm{C}$, and $0.37-1.75^{\circ} \mathrm{C}$ under RCP 4.5 (Figure $4(\mathrm{~b})$ ), and $0.30-0.86^{\circ} \mathrm{C}, 0.44-1.76^{\circ} \mathrm{C}$, and $0.76-2.70^{\circ} \mathrm{C}$ under RCP8.5 (Figure 4(c)) in the 2020s, 2050s, and 2080s, respectively. The greatest increase in temperature $\left(2.7^{\circ} \mathrm{C}\right)$ is anticipated in the month of June under the RCP8.5 scenario in the 2080s.

On the contrary, substantial decreases in temperature are predicted in March and April under both the RCP2.6 and RCP4.5 scenarios for future periods, with the greatest decrease $\left(-0.79^{\circ} \mathrm{C}\right)$ being seen in March under RCP8.5 in the 2020s.

Changes in mean seasonal temperature (compared with the base period 1954-1993) in Yunnan province under the three scenarios are shown in Figure 5. All the mean seasonal temperature increases in the future 90 years, except for spring in the 2020s, under all three scenarios, with more obvious changes in the summer and autumn. Overall, the maximum increase in temperature occurs in summer in all three future periods under the different scenarios, while the minimum increase occurs in spring. The patterns of increase are similar for mean monthly and seasonal temperatures. The decreases in spring in the 2020s are $-0.20,-0.11$, and $-0.16^{\circ} \mathrm{C}$ under the RCP2.6, RCP4.5, and RCP8.5 scenarios, respectively. However, in the 2020s, the minimum increase under all three scenarios is $0.19^{\circ} \mathrm{C}$ and the second-minimum is $0.22^{\circ} \mathrm{C}$, both occurring in autumn, which are high enough to offset the decrease in air temperature in spring. Therefore, the temperature will show an obviously increasing tendency in Yunnan province in the future.

(2) Variation of Annual Mean Air Temperature. Table 1 shows the changes in temperature for Yunnan province in the 2020s, 2050s, and 2080s with respect to the reference period under the RCP2.6, RCP4.5, and RCP8.5 scenarios obtained from the SDSM. Under the RCP2.6 scenario, the mean annual temperature will increase by $0.16,0.40$, and $0.53^{\circ} \mathrm{C}$ in the 2020s, 2050s, and 2080s, respectively. The increases under the RCP4.5 scenario are all greater than those under the RCP2.6 scenario. The maximum increases in the 2050s and 2080s are under the RCP8.5 scenario, as expected, but the biggest change in the 2020s is under the RCP4.5 scenario.

More details of changes in air temperature can be seen in Figure 6. It is clear that as time increases, the growth rate of temperature under the RCP8.5 scenario is the highest, followed by RCP 4.5 and RCP2.6. The magnitude of the increase in air temperature is insensitive to emission scenarios before about 2050. The moving average lines show an obvious difference after that, and a remarkable increase is projected for the RCP 8.5 scenario.

(3) Periodic Features of Air Temperature Time Series. Annual mean temperature from 1954 to 2100 was used to detect periodic features for Yunnan province. Here, only the result of wavelet analysis for RCP4.5 is illustrated (Figure 7), since the distribution patterns of the wavelet coefficients for different climate scenarios are similar. In Figure 7(a), the coefficients 


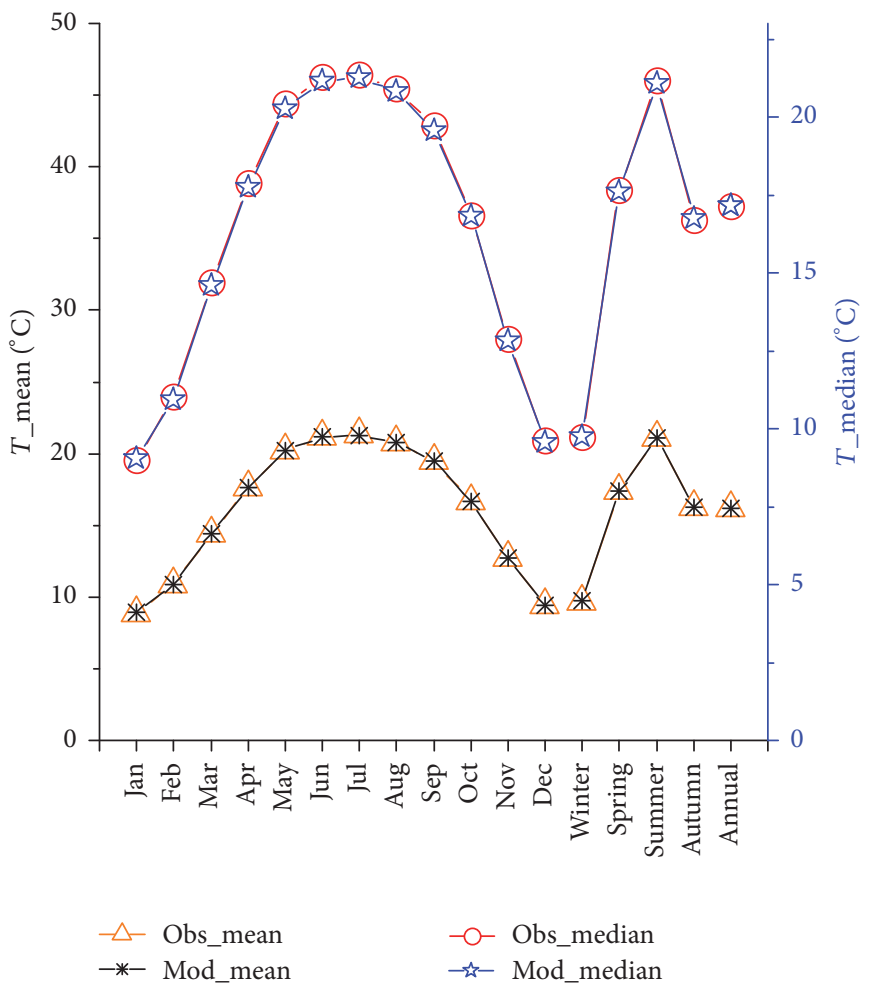

(a) Calibration

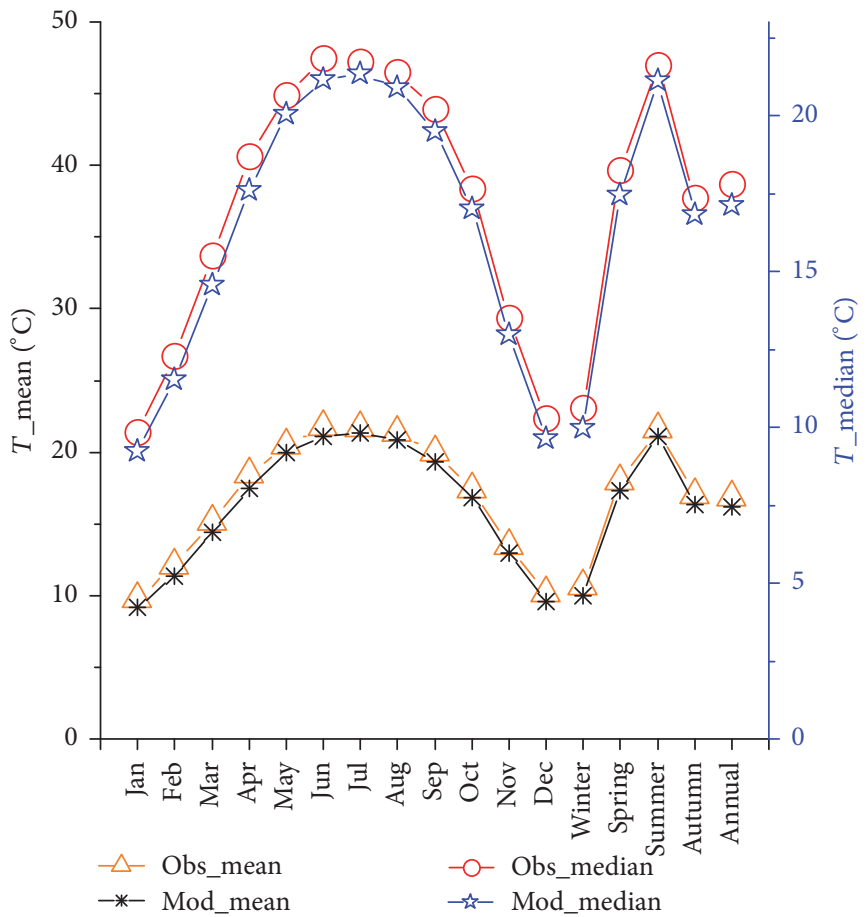

(b) Validation

Figure 2: Modeled and observed mean values of air temperature during calibration and validation periods. 


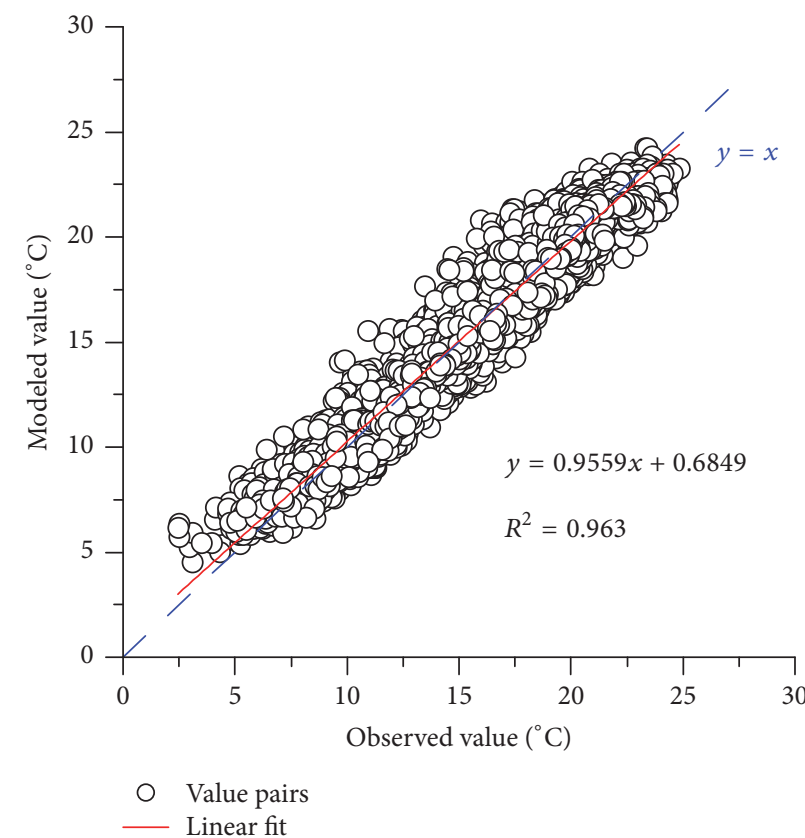

(a) Calibration

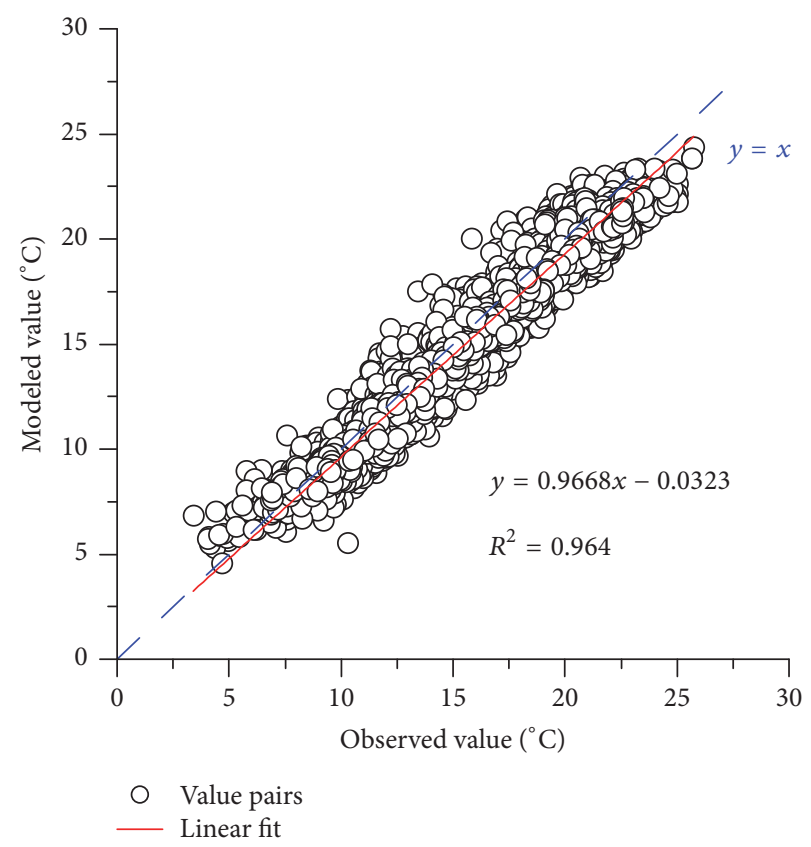

(b) Validation

FIGURE 3: Scatter plots of daily mean temperature between modeled and observed series during calibration and validation periods.

TABLE 1: Areal average of future daily temperature $\left({ }^{\circ} \mathrm{C}\right)$ compared with the base period.

\begin{tabular}{|c|c|c|c|c|c|c|c|c|c|}
\hline \multirow{3}{*}{$\begin{array}{l}\text { Observation } \\
\text { Base period }\end{array}$} & \multicolumn{9}{|c|}{ Projected air temperature } \\
\hline & \multicolumn{3}{|c|}{ RCP2.6 } & \multicolumn{3}{|c|}{ RCP 4.5} & \multicolumn{3}{|c|}{ RCP8.5 } \\
\hline & $2020 \mathrm{~s}$ & $2050 \mathrm{~s}$ & $2080 \mathrm{~s}$ & 2020 s & $2050 \mathrm{~s}$ & $2080 \mathrm{~s}$ & $2020 \mathrm{~s}$ & $2050 \mathrm{~s}$ & $2080 \mathrm{~s}$ \\
\hline 16.15 & 16.31 & 16.55 & 16.68 & 16.43 & 16.78 & 17.05 & 16.41 & 17.15 & 17.99 \\
\hline Increase & 0.16 & 0.40 & 0.53 & $0.27^{*}$ & 0.63 & 0.89 & 0.26 & $1.00^{*}$ & $1.84^{*}$ \\
\hline
\end{tabular}

Base period $=1954-1993 ; 2020 \mathrm{~s}=2011-2040 ; 2050 \mathrm{~s}=2041-2070 ; 2080 \mathrm{~s}=2071-2100 .{ }^{*}$ Maximum increases in 2020s, 2050s, and 2080s, respectively.

with positive values are plotted with a red solid line, which signifies a warm stage. The coefficients with negative values are plotted with a blue dash-dot line, which signifies a cold stage. The wavelet variance of the data is shown in Figure 7(b), in which the peak of the wavelet variance represents the dominant period of the signals, so the periodicity embedded in the data can be obtained by seeking all the maxima of the wavelet variance.

Figure 7(a) reveals a cold stage from 1970 to 2030 and then a warm stage until 2100 on a centurial scale. From Figure $8(\mathrm{~b})$, it can be seen that the dominant periods of the annual mean temperature are $4,6,12,21,50,83$, and 125 years, of which the 4-, 6-, and 125-year periods are significant at a $95 \%$ confidence level, while the 12 -year period is significant at a $90 \%$ confidence level and the remaining periods are not significant at a $90 \%$ significance level.

The air temperature under different scenarios shows slightly diverse dominant periods (Table 2). The RCP2.6 scenario has dominant periods of 3, 6, 10, 22, 39, 47, 79, and 125 years, of which the 39 -year period is significant at a $90 \%$ confidence level, the 47 -year period is not significant at a $90 \%$ confidence level, and the remaining periods are significant at a 95\% significance level. The RCP8.5 scenario has dominant
TABLE 2: Main periods $(T)$ under the three emission scenarios.

\begin{tabular}{lccc}
\hline Main period & RCP2.6 & RCP 4.5 & RCP8.5 \\
\hline$T_{1}$ & $3^{* *}$ & $4^{* *}$ & 4 \\
$T_{2}$ & $6^{* *}$ & $6^{* *}$ & 6 \\
$T_{3}$ & $10^{* *}$ & $12^{*}$ & 13 \\
$T_{4}$ & $22^{* *}$ & 21 & - \\
$T_{5}$ & $39^{*}$ & - & 35 \\
$T_{6}$ & 47 & 50 & 53 \\
$T_{7}$ & $79^{* *}$ & 83 & 83 \\
$T_{8}$ & $125^{* *}$ & $125^{* *}$ & $125^{* *}$ \\
\hline
\end{tabular}

${ }^{*} 90 \%$ confidence level; ${ }^{* *} 95 \%$ confidence level.

periods of $4,6,13,35,53,83$, and 125 years, of which only the 125 -year period is significant at a $95 \%$ confidence level, while all the others are not significant at a $90 \%$ confidence level. Furthermore, the main differences are between $T_{4}$ and $T_{5}$ under the three scenarios. In contrast, RCP2.6 has all eight dominant periods, but RCP4.5 lacks the $T_{5}$ period and RCP8.5 lacks $T_{4}$. These differences might indicate the different response behaviors of local meteorological conditions under different emission scenarios of global climate change. 


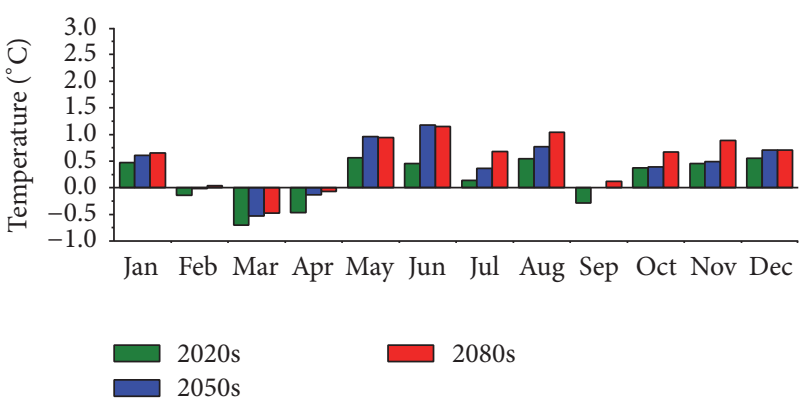

(a) RCP2.6
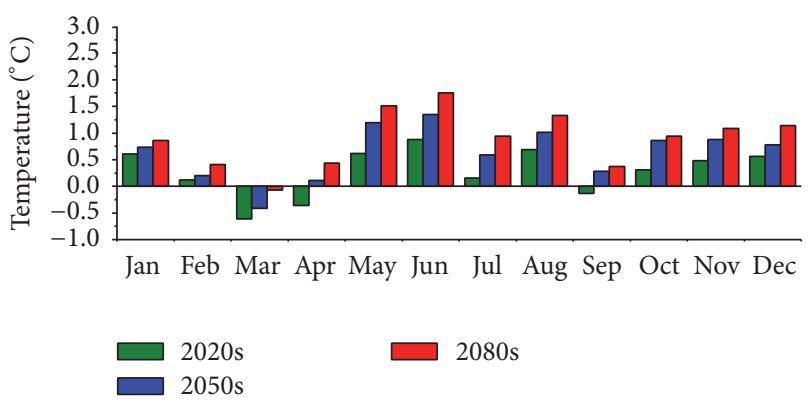

$\square 2080$ s

(b) RCP4.5

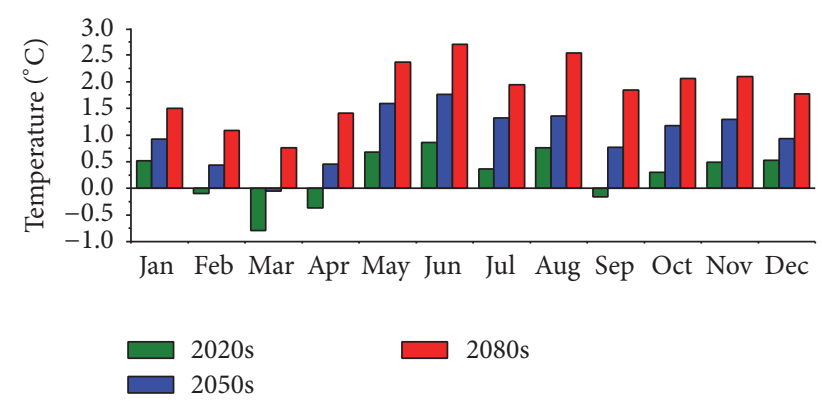

(c) RCP8.5

FIGURE 4: Mean monthly changes in projected temperature with respect to the base period under three scenarios.

4.2.2. Spatial Patterns of Air Temperature. The spatial distributions of future changes in annual mean temperature in Yunnan province (compared with the base period) under the RCP2.6, RCP4.5, and RCP8.5 scenarios were obtained by a radial basis function (RBF) interpolation technique using the ArcGIS10.1 software package. The results for the annual changes are shown in Figure 8, in which remarkable spatial differences in the changes can be seen.

On the whole, most of the province may experience an obviously increasing trend in the three future periods under all three scenarios. However, a few areas, including some patches from the center of Yunnan, such as Kunming and Yuxi, are expected to show a negative trend. With the passage of the decades (2020s, 2050s, and 2080s), the increase will be greater, and the area of higher temperature will grow in size.

In the 2020s (Figures $8(\mathrm{a}), 8(\mathrm{~d})$, and $8(\mathrm{~g})$ ), the spatial distribution of the decrease in air temperature will be similar under all three scenarios, with Kunming, Yuxi, northeastern Simao, and southeastern Zhaotong experiencing cooling. Furthermore, the maximum cooling is located over parts of

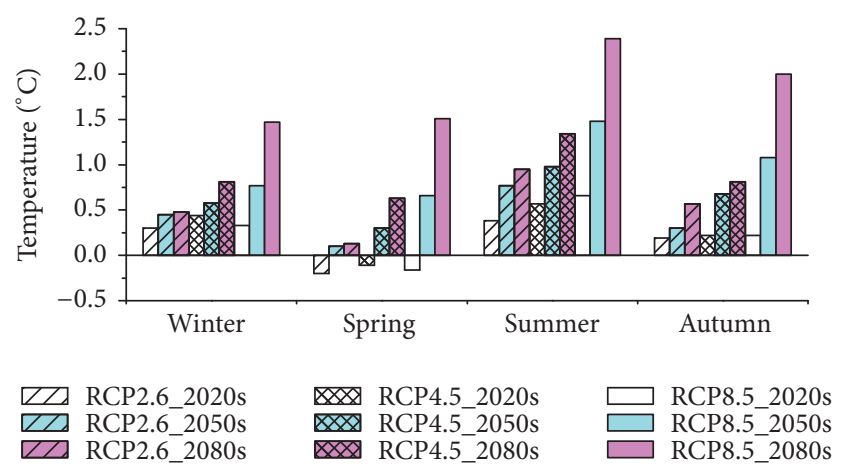

FIGURE 5: Mean seasonal changes in projected temperature with respect to the base period under three scenarios.

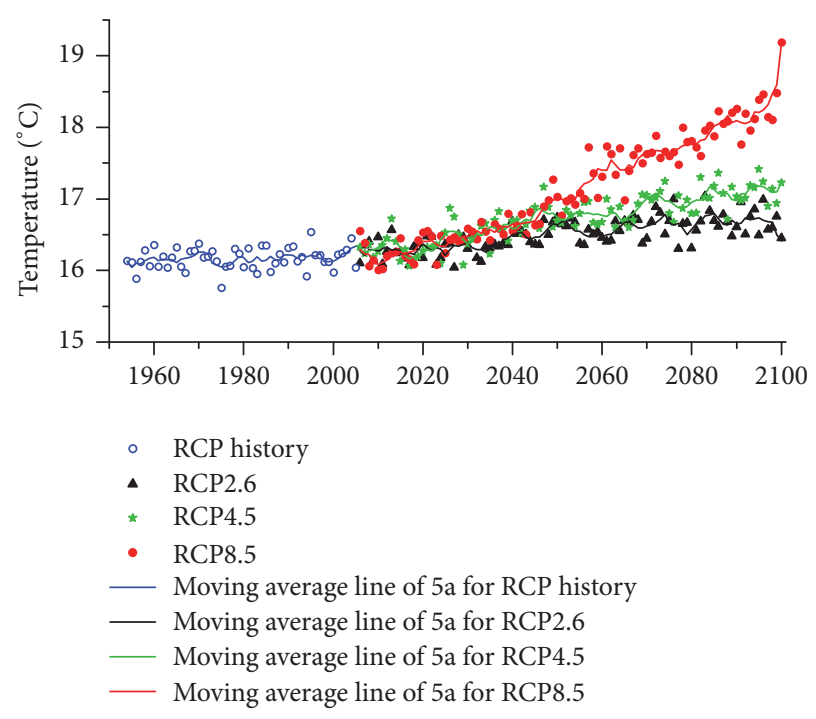

Note: RCP history, 1954-2005

Figure 6: Annual mean temperature series in Yunnan province under three scenarios.

Kunming and Yuxi, reaching $-0.5^{\circ} \mathrm{C}$. In addition, a few parts of western and eastern Yunnan, such as northern Diqing, Nujiang, Lijiang, Qujing, and Wenshan may experience greater rises in temperature $\left(0.5-1.0^{\circ} \mathrm{C}\right)$. A slightly increasing trend $\left(0-0.5^{\circ} \mathrm{C}\right)$ is expected in the remaining areas, which account for about half of the province.

For the 2050s (Figures $8(\mathrm{~b}), 8(\mathrm{e})$, and $8(\mathrm{~h})$ ), the area experiencing cooling $\left(<0^{\circ} \mathrm{C}\right)$ is smaller than in the 2020s and is mainly located over parts of Kunming and Yuxi. The annual mean temperature will increase by amounts in the range $0.5-1.5^{\circ} \mathrm{C}$ in most parts of Yunnan under both RCP4.5 and RCP8.5. Under RCP2.6, the area of warming $\left(0.5-1.0^{\circ} \mathrm{C}\right)$ is mainly located over northwestern and southeastern Yunnan, with the remaining parts experiencing slight warming (0$\left.0.5^{\circ} \mathrm{C}\right)$.

In the 2080s (Figures 8(c), 8(f), and 8(i)), the area of cooling $\left(<0^{\circ} \mathrm{C}\right)$ will disappear under RCP8.5, and the annual mean temperature in northwestern and eastern Yunnan will increase by more than $1^{\circ} \mathrm{C}$ under both RCP4.5 and RCP8.5. 


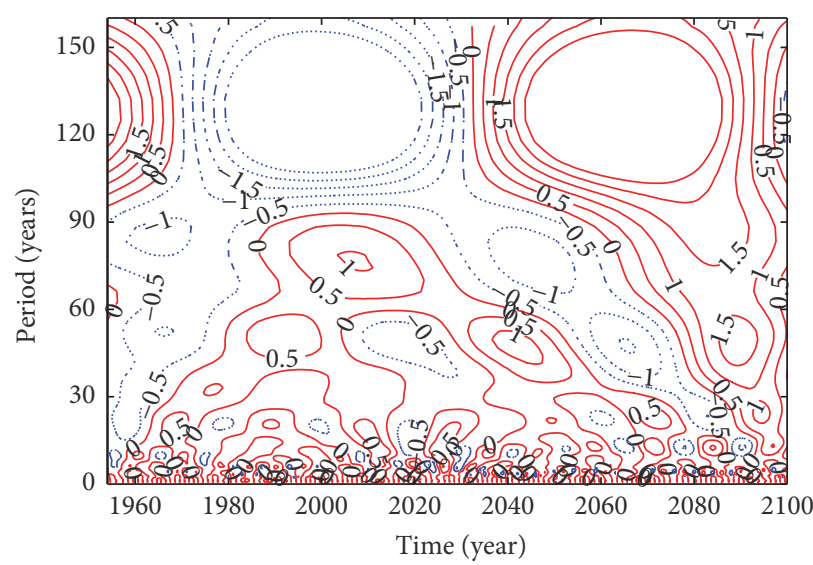

(a) The real part of the wavelet coefficient contour map

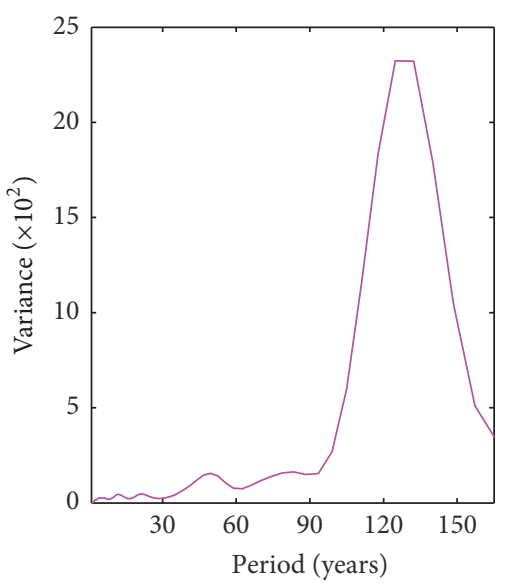

(b) Wavelet variance diagram

FIGURE 7: Results of wavelet analysis under the RCP4.5 scenario.

In particular, the increase will be larger than $2.0^{\circ} \mathrm{C}$ in nearly one-third of Yunnan province under RCP8.5. In addition, the maximum increase will be greater than $2.5^{\circ} \mathrm{C}$ in parts of Diqing, Lijiang, Chuxiong, and Qujing.

Under the different scenarios, in general, the increase in air temperature under RCP8.5 will be highest, followed by that under RCP4.5 and by that under RCP2.6.

4.3. Discussion. Statistical downscaling methods, as effective measures, are generally used to construct the bridge between large-scale atmospheric variables from GCM output and local-scale climate response; among these methods, the SDSM is widely used owing to its simplicity and superior capabilities, as well as the free availability of the required software [14, 22]. Public awareness of climate change has recently increased sharply across the world, but knowledge of climate change is still insufficient, particularly in regions like the Yunnan Plateau, at high elevation, crossed by the Tropic of Cancer, and showing large differences in temperature in mountainous areas.

The SDSM generally performs better in reproducing temperature than rainfall and evaporation $[5,15,46]$, so the study has focused on just the future temperature in Yunnan province. In consideration of the long period of modeling, about 90 years from 2011 to 2100 , the calibration period should be as long as possible, so that the proposed models can achieve a good hit ratio and accuracy. In addition, the observational data are from 1954 to 2014, and hence the study took the calibration period as the 40 years from 1954 to 1993 and the validation period as the 21 years from 1994 to 2014 . These calibration and validation periods are longer than those commonly used, such as 1961-1990 (e.g., Wang et al., 2012 [35]) or 1971-2000 for calibration and 1991-2000 or 2001-2010 (e.g., Liu et al., 2015 [47]) for validation. As a consequence, the future temperature should be accurately projected by the calibrated SDSM.

In further studies, the results obtained here need to be subjected to a comprehensive comparison with the outputs of other GCM models to achieve greater reliability in terms of future projections. In particular, analyses of the uncertainties related to the model and the GCM data are needed for a more profound understanding of the future changes in predictands.

\section{Conclusions}

This paper has presented future projections of air temperature in the Yunnan Plateau over the twenty-first century under the RCP2.6, RCP4.5, and RCP8.5 emission scenarios from the MRI using the SDSM. The study has investigated the applicability of the SDSM by downscaling the mean air temperature, which is important for assessing the impact of climate change on evapotranspiration and the hydrologic cycle. Changes in daily mean temperature have been addressed to provide better understanding of future changes in climate extremes in this region. Furthermore, the study has analyzed the patterns of change for the 2020s, 2050s, and 2080s, which should help government make policy on extreme climate events and agriculture and also pave the way for the study of hydrological impacts under future climate change in the middle and lower reaches of the Lancang River basin. The major conclusions can be summarized as follows:

(1) The SDSM showed good applicability to the simulation of air temperature in Yunnan both for individual stations and for the whole region. During the calibration period, the maximum relative errors (MREs) were $0.65 \%$ and $0.77 \%$ for mean and median air temperature over 12 months, and $0.28 \%$ and $0.37 \%$ for mean and median air temperature over all seasons. For the validation period, the MREs were $-6.16 \%$ and $-6.23 \%$ for mean and median air temperature over 12 months and $-6.09 \%$ and $-5.89 \%$ for mean and median air temperature over all seasons. The monthly submodel of the SDSM was found to be effective for downscaling of air temperature, with high correlations $\left(R^{2}=0.963\right.$ for calibration and $R^{2}=0.964$ for validation) being obtained between downscaled and observed daily mean temperature data. Taken 


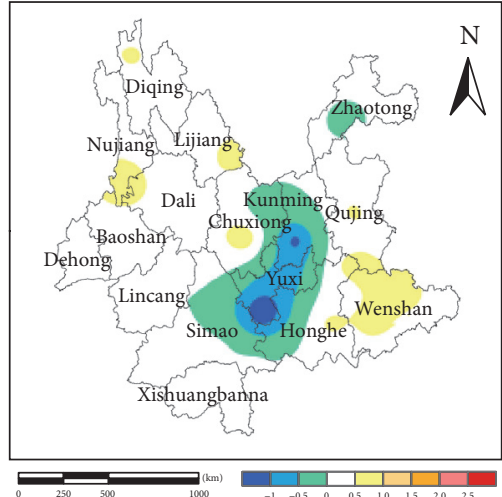

(a) RCP2.6_2020s

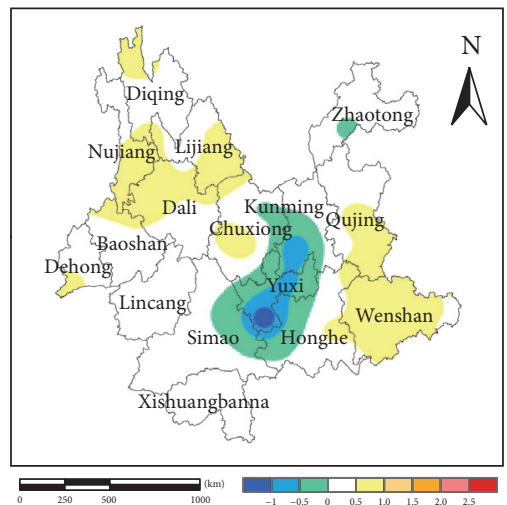

(d) RCP4.5_2020s

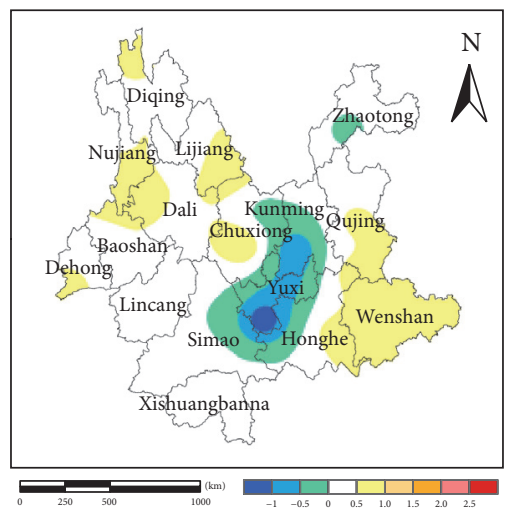

(g) RCP8.5_2020s

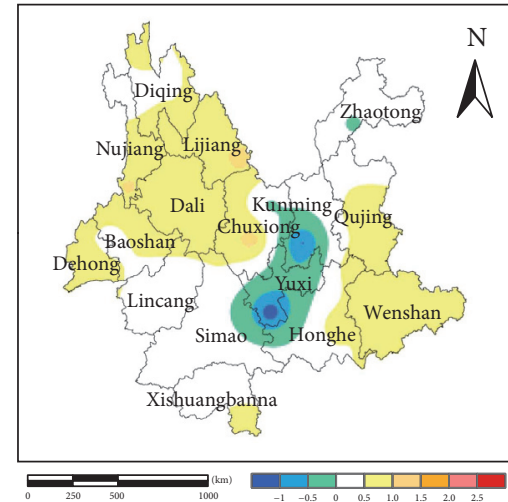

(b) RCP2.6_2050s

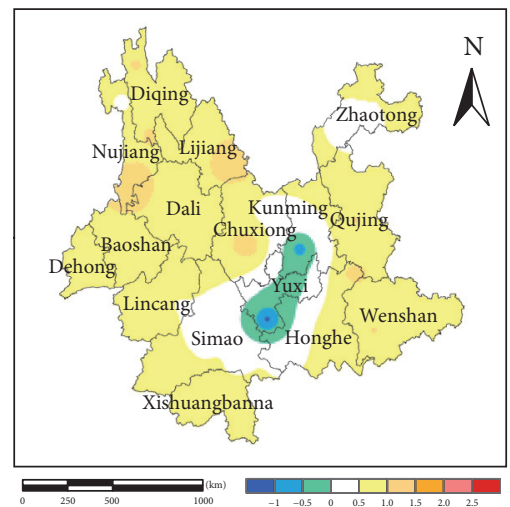

(e) RCP4.5_2050s

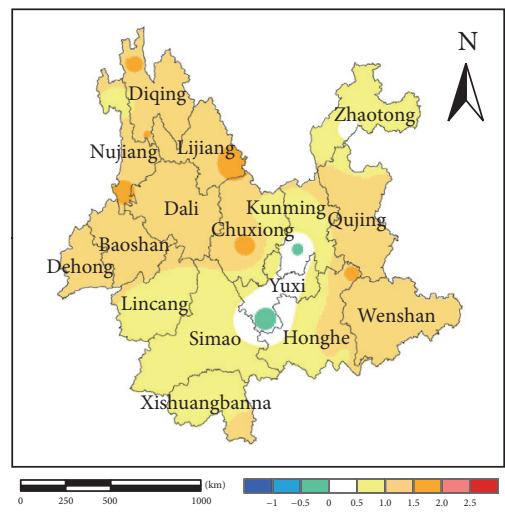

(h) RCP8.5_2050s

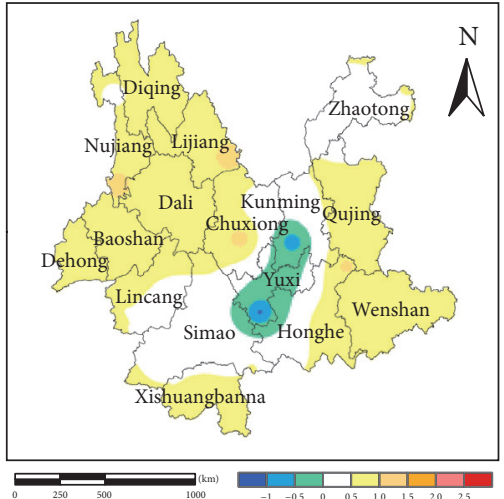

(c) RCP2.6_2080s

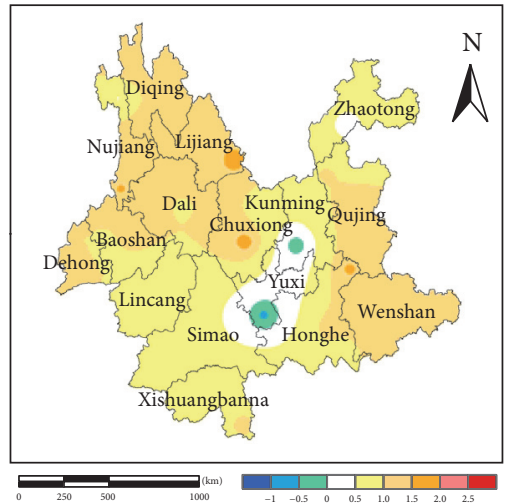

(f) RCP4.5_2080s

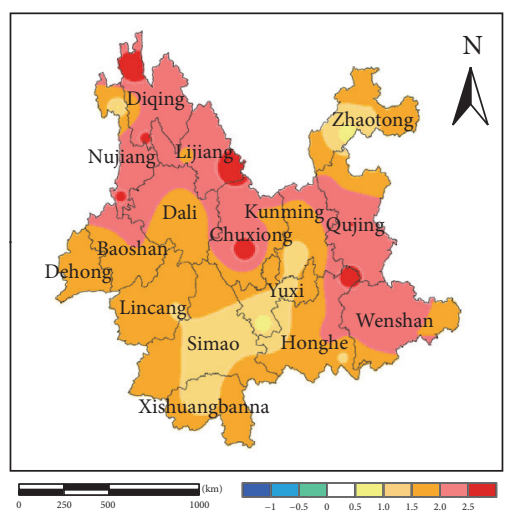

(i) RCP8.5_2080s

FIGURE 8: Spatial distribution of the increase in annual mean temperature in Yunnan province under three scenarios.

together, using selected predictors and feeding them to the SDSM, the variational characteristics of the mean air temperature could be reasonably predicted for Yunnan province.

(2) The projected results of future air temperature showed that the monthly mean temperature of three future periods would all increase with different magnitudes under the three different scenarios compared with the base period, except for March and April. The increase under RCP8.5 was the highest for all months. On average, June showed the most obvious increase among the 12 months. Seasonally, air temperature would decline slightly in spring in the 2020s and clearly increase in the other seasons. Moreover, the greatest change would occur in the summer and the least change in spring. Annually, on average, the most remarkable changes in the 2020s, 2050s, and 2080s were $0.27,1.00$, and $1.84^{\circ} \mathrm{C}$, respectively. The annual air temperature from 1954 to 2100 in Yunnan under the different scenarios showed similar periodicity, with seven periods, but under the RCP2. 6 scenario, there were eight periods. Typical 22- and 39-year periods appeared under RCP2.6 and a typical 21-year period 
under RCP4.5, while an alternative period of 35 years appeared under RCP8.5.

(3) On the whole, the annual mean temperature in most parts of Yunnan would be dominated by increasing trends during all of the future periods under all three scenarios, with the magnitude and percentage of increase being greatest in the 2080s under RCP8.5. Furthermore, there would be a more distinct increase in northwest and southeast Yunnan in most future periods, whereas there would be a significant decrease in the center of Yunnan (e.g., Yuxi and Kunming). This may be partly because of the abnormal conditions caused by special terrain and, on the other hand, a result of the influence of the distribution of nine plateau lakes. Five of these lakes (accounting for approximately $59.87 \%$ of the total area of the nine), namely, Dianchi, Fuxian, Qilu, Xingyun, and Yangzong, are located in Yuxi and Kunming, and their surface water will absorb heat from the air by evaporation, thereby limiting or retarding rises in temperature.

\section{Competing Interests}

The authors declare that they have no competing interests.

\section{Acknowledgments}

This research was supported by the National Natural Science Foundation of China (no. 91547114) and the National Water Pollution Control and Treatment Science and Technology Major Project (no. 2013ZX07102-006-04). The authors would like to express their gratitude to the following projects and data centers: the National Meteorological Information Center in Beijing for providing valuable station climate datasets and the Intergovernmental Panel on Climate Change for providing the MRI/CGCM3 model output data. Furthermore, the authors would like to thank the following individuals: Professor R. L. Wilby from Loughborough University, UK, for providing SDSM software and NCEP reanalysis datasets, and Sun Zhen and Yin Yuan-yuan from the Institute of Geographic Sciences and Natural Resources Research and Liang Li-qiao from the Institute of Tibetan Plateau Research, CAS, for providing comments.

\section{References}

[1] T. F. Stocker, Climate Change 2013: The Physical Science Basis: Working Group I Contribution to the Fifth Assessment Report of the Intergovernmental Panel on Climate Change, Cambridge University Press, 2014.

[2] IPCC, Summary for Policymakers//Climate Change 2013: The Physical Science Basis. Contribution of Working Group I to the Fifth Assessment Report of the Intergovernmental Panel on Climate Change, Cambridge University Press, 2013.

[3] D. H. Qin and T. Stocker, "Highlights of the IPCC working group I fifth assessment report," Advances in Climate Change Research, vol. 10, no. 1, pp. 1-6, 2014 (Chinese).
[4] Y. Hundecha and A. Bárdossy, "Statistical downscaling of extremes of daily precipitation and temperature and construction of their future scenarios," International Journal of Climatology, vol. 28, no. 5, pp. 589-610, 2008.

[5] R. Mahmood and M. S. Babel, "Evaluation of SDSM developed by annual and monthly sub-models for downscaling temperature and precipitation in the Jhelum basin, Pakistan and India," Theoretical and Applied Climatology, vol. 113, no. 1-2, pp. 27-44, 2013.

[6] B. Su, J. Huang, M. Gemmer et al., "Statistical downscaling of CMIP5 multi-model ensemble for projected changes of climate in the Indus River Basin," Atmospheric Research, vol. 178-179, pp. 138-149, 2016.

[7] B. Sivakumar and G. Christakos, "Climate: patterns, changes, and impacts," Stochastic Environmental Research and Risk Assessment, vol. 25, no. 4, pp. 443-444, 2011.

[8] H. J. Fowler, S. Blenkinsop, and C. Tebaldi, "Linking climate change modelling to impacts studies: recent advances in downscaling techniques for hydrological modelling," International Journal of Climatology, vol. 27, no. 12, pp. 1547-1578, 2007.

[9] T. Yang, H. Li, W. Wang, C.-Y. Xu, and Z. Yu, "Statistical downscaling of extreme daily precipitation, evaporation, and temperature and construction of future scenarios," Hydrological Processes, vol. 26, no. 23, pp. 3510-3523, 2012.

[10] R. L. Wilby, L. E. Hay, W. J. Gutowski Jr. et al., "Hydrological responses to dynamically and statistically downscaled climate model output," Geophysical Research Letters, vol. 27, no. 8, pp. 1199-1202, 2000.

[11] R. L. Wilby and T. M. L. Wigley, "Downscaling general circulation model output: a review of methods and limitations," Progress in Physical Geography, vol. 21, no. 4, pp. 530-548, 1997.

[12] B. C. Hewitson and R. G. Crane, "Climate downscaling: techniques and application," Climate Research, vol. 7, no. 2, pp. 8595, 1996.

[13] R. L. Wilby, C. W. Dawson, and E. M. Barrow, "SDSM-a decision support tool for the assessment of regional climate change impacts," Environmental Modelling \& Software, vol. 17, no. 2, pp. 147-159, 2002.

[14] J. Tang, X. Niu, S. Wang, H. Gao, X. Wang, and J. Wu, "Statistical downscaling and dynamical downscaling of regional climate in China: present climate evaluations and future climate projections," Journal of Geophysical Research: Atmospheres, vol. 121, no. 5, pp. 2110-2129, 2016.

[15] Z. Hassan, S. Shamsudin, and S. Harun, "Application of SDSM and LARS-WG for simulating and downscaling of rainfall and temperature," Theoretical and Applied Climatology, vol. 116, no. 1-2, pp. 243-257, 2014.

[16] M. Z. Hashmi, A. Y. Shamseldin, and B. W. Melville, "Comparison of SDSM and LARS-WG for simulation and downscaling of extreme precipitation events in a watershed," Stochastic Environmental Research and Risk Assessment, vol. 25, no. 4, pp. 475-484, 2011.

[17] J. Chen, F. P. Brissette, and R. Leconte, "Assessing regressionbased statistical approaches for downscaling precipitation over North America," Hydrological Processes, vol. 28, no. 9, pp. 34823504, 2014.

[18] Z. E. Asong, M. N. Khaliq, and H. S. Wheater, "Projected changes in precipitation and temperature over the Canadian Prairie Provinces using the Generalized Linear Model statistical downscaling approach," Journal of Hydrology, vol. 539, pp. 429446, 2016. 
[19] Y. Hu, S. Maskey, and S. Uhlenbrook, "Expected changes in future temperature extremes and their elevation dependency over the Yellow River source region," Hydrology and Earth System Sciences, vol. 17, no. 7, pp. 2501-2514, 2013.

[20] J. T. Chu, J. Xia, C.-Y. Xu, and V. P. Singh, "Statistical downscaling of daily mean temperature, pan evaporation and precipitation for climate change scenarios in Haihe River, China," Theoretical and Applied Climatology, vol. 99, no. 1-2, pp. 149-161, 2010.

[21] Z. Liu, Z. Xu, S. P. Charles, G. Fu, and L. Liu, "Evaluation of two statistical downscaling models for daily precipitation over an arid basin in China," International Journal of Climatology, vol. 31, no. 13, pp. 2006-2020, 2011.

[22] J. Huang, J. Zhang, Z. Zhang, S. Sun, and J. Yao, "Simulation of extreme precipitation indices in the Yangtze River basin by using statistical downscaling method (SDSM)," Theoretical and Applied Climatology, vol. 108, no. 3-4, pp. 325-343, 2012.

[23] L. Liu, Z. Liu, X. Ren, T. Fischer, and Y. Xu, "Hydrological impacts of climate change in the Yellow River Basin for the 21st century using hydrological model and statistical downscaling model," Quaternary International, vol. 244, no. 2, pp. 211-220, 2011.

[24] Z. X. Xu, X. J. Yang, D. P. Zuo, Q. Chu, and W. F. Liu, "Spatiotemporal characteristics of extreme precipitation and temperature: a case study in Yunnan Province, China," in Proceedings of the International Association of Hydrological Sciences (IAHS '15), vol. 369, pp. 121-127, Yunnan Province, China, July 2015.

[25] Editorial Committee for Physical Geography of ChinaPalaeogeography, Science Press, 1984 (Chinese).

[26] E. Kalnay, M. Kanamitsu, R. Kistler et al., "The NCEP/NCAR 40-year reanalysis project," Bulletin of the American Meteorological Society, vol. 77, no. 3, pp. 437-471, 1996.

[27] R. Kistler, E. Kalnay, W. Collins et al., "The NCEP-NCAR 50year reanalysis: monthly means CD-ROM and documentation," Bulletin of the American Meteorological Society, vol. 82, no. 2, pp. 247-267, 2001.

[28] R. L. Wilby, C. W. Dawson, C. Murphy, P. O’Connor, and E. Hawkins, "The Statistical DownScaling Model-Decision Centric (SDSM-DC): conceptual basis and applications," Climate Research, vol. 61, no. 3, pp. 259-276, 2014.

[29] S. Yukimoto, Y. Adachi, M. Hosaka et al., "A new global climate model of the meteorological research institute: MRICGCM3-model description and basic performance," Journal of the Meteorological Society of Japan, vol. 90, no. 2, pp. 23-64, 2012.

[30] K. Venkataraman, S. Tummuri, A. Medina, and J. Perry, “21st century drought outlook for major climate divisions of texas based on CMIP5 multimodel ensemble: implications for water resource management," Journal of Hydrology, vol. 534, pp. 300316, 2016.

[31] R. L. Wilby and C. W. Dawson, "The statistical downscaling model: insights from one decade of application," International Journal of Climatology, vol. 33, no. 7, pp. 1707-1719, 2013.

[32] F. Wetterhall, A. Bádossy, D. Chen, S. Halldin, and C.-Y. Xu, "Daily precipitation-downscaling techniques in three Chinese regions," Water Resources Research, vol. 42, no. 11, Article ID W11423, 2006.

[33] R. L. Wilby, P. G. Whitehead, A. J. Wade, D. Butterfield, R. J. Davis, and G. Watts, "Integrated modelling of climate change impacts on water resources and quality in a lowland catchment: River Kennet, UK," Journal of Hydrology, vol. 330, no. 1-2, pp. 204-220, 2006.
[34] M. Sigdel and Y. Ma, "Evaluation of future precipitation scenario using statistical downscaling model over humid, subhumid, and arid region of Nepal-a case study," Theoretical and Applied Climatology, vol. 123, no. 3-4, pp. 453-460, 2016.

[35] X. Wang, T. Yang, Q. Shao, K. Acharya, W. Wang, and Z. $\mathrm{Yu}$, "Statistical downscaling of extremes of precipitation and temperature and construction of their future scenarios in an elevated and cold zone," Stochastic Environmental Research and Risk Assessment, vol. 26, no. 3, pp. 405-418, 2012.

[36] L. Liang, L. Li, C. Liu, and L. Cuo, "Climate change in the Tibetan plateau three rivers source region: 1960-2009," International Journal of Climatology, vol. 33, no. 13, pp. 29002916, 2013.

[37] C. Suteanu, "Statistical variability and persistence change in daily air temperature time series from high latitude arctic stations," Pure and Applied Geophysics, vol. 172, no. 7, pp. 20572073, 2015.

[38] R. S. Pathak and A. Singh, "Mexican hat wavelet transform of distributions," Integral Transforms and Special Functions, vol. 27, no. 6, pp. 468-483, 2016.

[39] W. Emery and R. Thomson, "Data analysis methods in physical oceanography," Oceanographic Literature Review, vol. 1, no. 45, p. 2, 1998.

[40] R. E. Thomson and W. J. Emery, Data analysis methods in physical oceanography, Newnes, 2014.

[41] C. Torrence and G. P. Compo, "A practical guide to wavelet analysis," Bulletin of the American Meteorological Society, vol. 79, no. 1, pp. 61-78, 1998.

[42] D. B. Percival and A. T. Walden, Wavelet Methods for Time Series Analysis, vol. 4, Cambridge University Press, 2006.

[43] Q. S. Ge, J. Liu, and X. Q. Fang, "General characteristics of temperature change and centennial warm periods during the past 2000 years," Acta Geographica Sinica, vol. 68, no. 5, pp. 579592, 2013 (Chinese).

[44] K. Qian, X.-S. Wang, J. Lv, and L. Wan, “The wavelet correlative analysis of climatic impacts on runoff in the source region of Yangtze River, in China," International Journal of Climatology, vol. 34, no. 6, pp. 2019-2032, 2014.

[45] H. Zhao, L. Gong, H. Qu, H. Zhu, X. Li, and F. Zhao, "The climate change variations in the northern Greater Khingan Mountains during the past centuries," Journal of Geographical Sciences, vol. 26, no. 5, pp. 585-602, 2016.

[46] D. Singh, S. K. Jain, and R. D. Gupta, "Statistical downscaling and projection of future temperature and precipitation change in middle catchment of Sutlej River Basin, India," Journal of Earth System Science, vol. 124, no. 4, pp. 843-860, 2015.

[47] S. Liu, Q. Huang, Y. Wang, Y. Xie, Y. Ren, and J. Li, "Simulation and prediction of climatic elements in Jinghe River basin using downscaling method and CMIP5," Transactions of the Chinese Society of Agricultural Engineering, vol. 31, no. 23, pp. 138-144, 2015 (Chinese). 

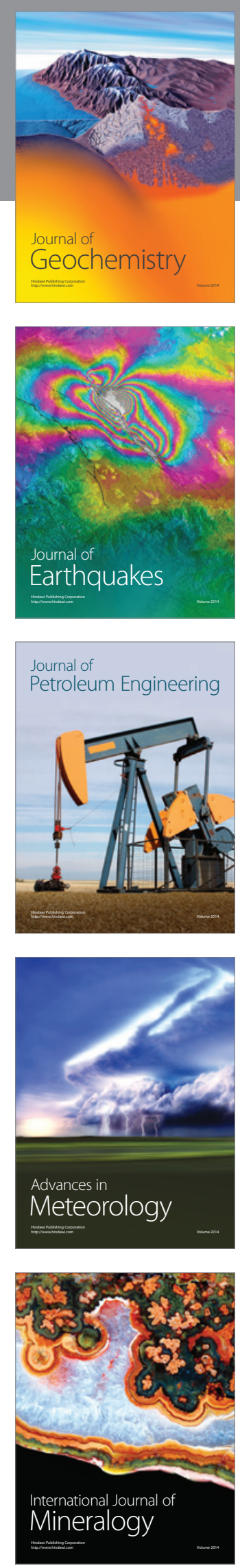
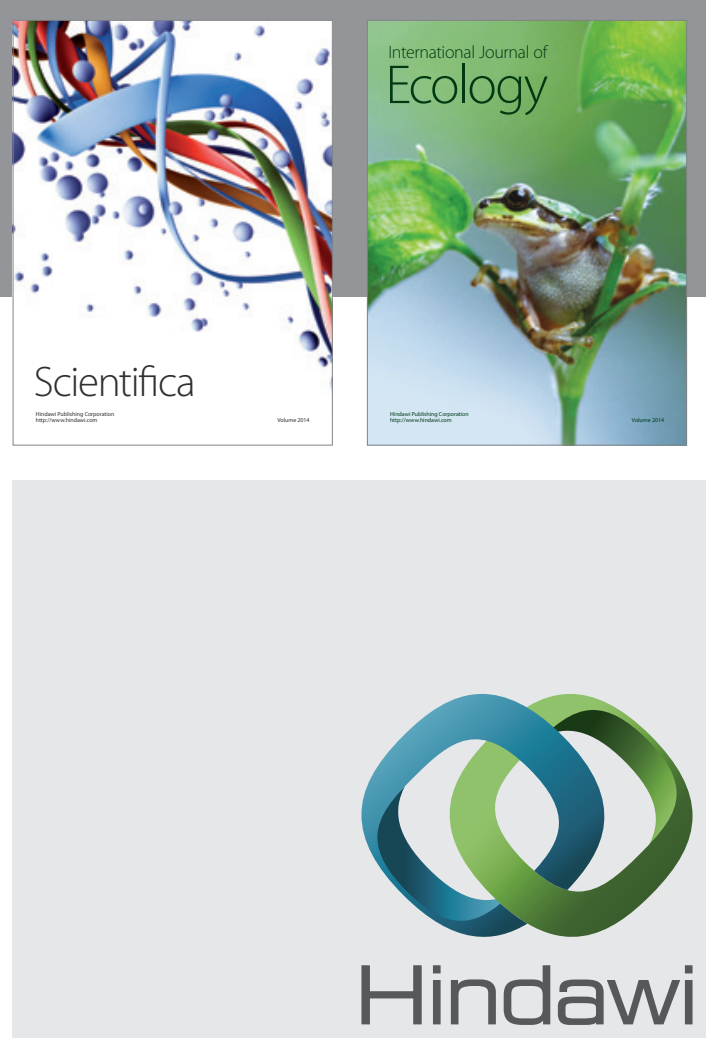

Submit your manuscripts at

https://www.hindawi.com
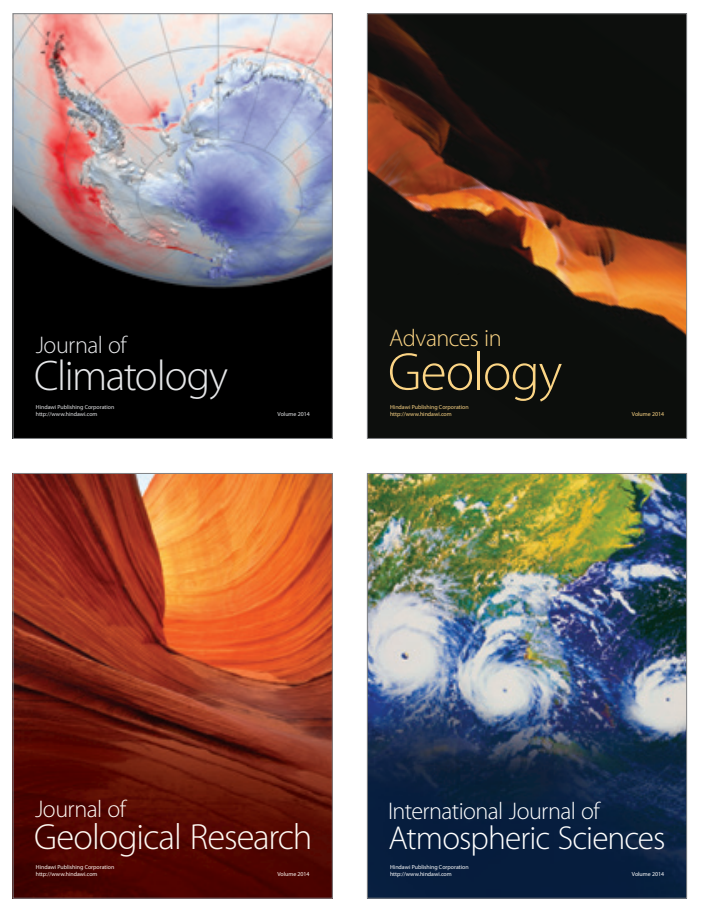

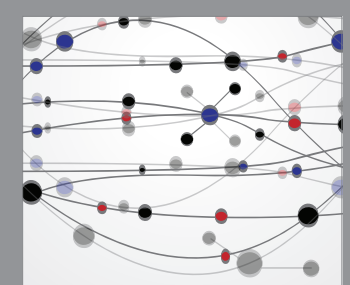

The Scientific

\section{World Journal}
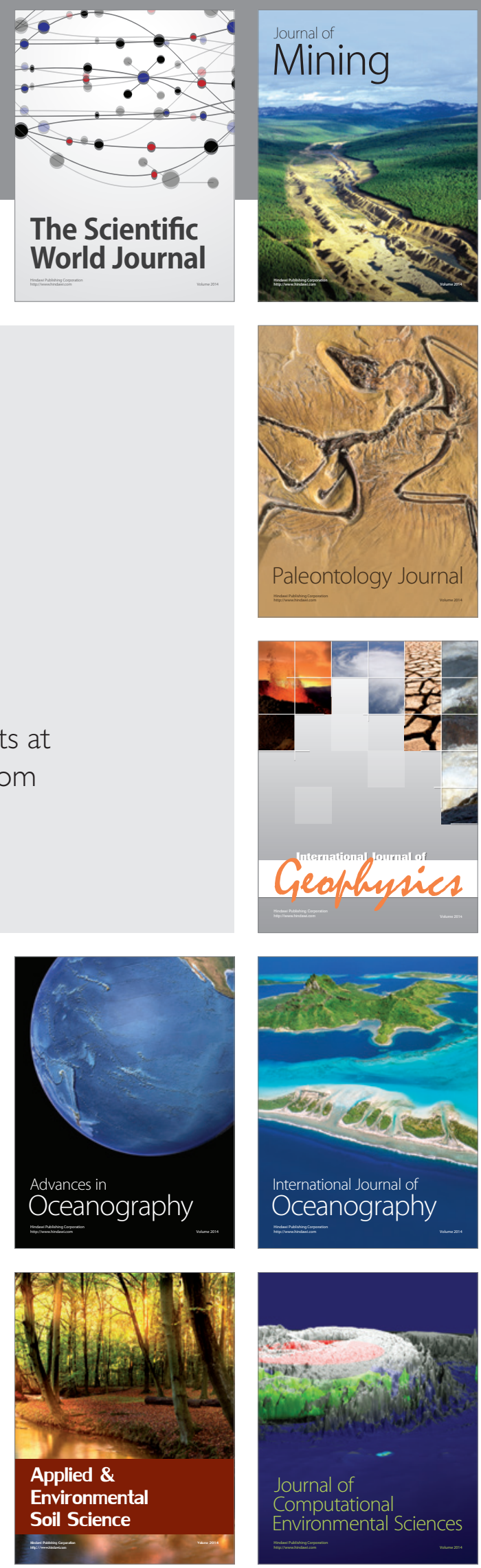